\title{
Understanding Moral Imagination: Applying A Network State Framework to Cases of Inventing for the Environment
}

\author{
Matthew M. Mehalik, Michael E. Gorman \\ University of Virginia
}

\begin{abstract}
We discuss a network state framework to highlight the decision choices and actions of a group of entrepreneurs who are struggling to do well by doing good by inventing for the environment and global development. The framework helps explain the relationship of moral imagination and the ability to take action after engaging in it given the context of a practitioner's network relationships. The framework is used as a tool to help engineering students develop skills at integrating moral imagination into their context of decision making.
\end{abstract}

\section{Framework}

In engineering education we desire our students to develop a skill in exercising moral imagination by having them shift perspectives when discussing real-world cases ${ }^{1}$. We are proposing that this process can be improved if we provide our students with a framework to help them structure analysis of the contextual, organizational, and network issues and constraints that make exercising moral imagination difficult in practice.

The framework we discuss consists of three network states:

1. A state in which one actor or small elite group of actors has the overall problem representation and black boxes others into specific roles whose purpose those persons only partly understand.

2. A state in which no group of actors has a comprehensive view and in which all are connected by a boundary object that each actor sees differently. In State 2 individual actors can be pursuing their own enterprises in relation to a common boundary object. Successful networks in this kind of state include active trading zones. Unsuccessful networks include ones in which the creole connecting the zones fails, forcing the network to move into another state or dissociate altogether ${ }^{2}$.

3. A state in which all participants need to share a common representation.

Networks can shift among these states, and the states also depend on where one draws the practitioner network boundaries. The states can be viewed as a continuum, based on the type of trading zone involved. In State 1 there is only the most unequal kind of trade. A State 1 network can shift into unfair State 2's, where the trades do not take place on a level basis. As networks

Proceedings of the 2001 American Society for Engineering Education Annual Conference \& Exposition Copyright (C) 2001, American Society for Engineering Education 
approach State 3, the trades are fairer, and there is a higher level of mutual understanding and trust, until finally one reaches a State 3 , where all negotiations involve a shared understanding and commitment. The network focus builds upon the work of Hutchins ${ }^{3}$, Latour ${ }^{4}$, and Law and Callon 5 .

\section{State 1 Networks}

Engineering and other practitioners lack moral imagination in State 1 networks.

The elite actor or group of actors has no interest in sharing their representation of the way an issue is approached. By controlling the representation and the kind of relationships others can have with the representation, this group works continuously to make sure it stays in control to the exclusion of others. The boundaries that constitute a valid trade are dictated solely by the elite actor or group. Because the elite group has no interest in other perspectives on an issue other than to the extent they represent a threat to their exclusive control, they lack moral imagination.

On the flip side of a State 1 network, those members who do not possess the problem representation also lack moral imagination with respect to the representation. This group of actors usually finds itself confined, or black boxed, to very narrowly defined roles with limited agency, with respect to the represented issue. Often, members of this group lack the awareness that they even have an issue relationship that is based on such exclusivity, or even that the issue itself even exists. Because of these limitations it is difficult for alternative perspectives to be traded, and thus it is difficult to develop or exercise moral imagination. The result is that neither side in this unequal relationship understands the other.

State 1 networks are inherently unstable. They have to be maintained by coercion ${ }^{6}$. The elite actor or actors remain vigilant to discourage any trading of alternative perspectives; however, this is usually very difficult in practice because the excluded group can often develop and trade alternative perspectives. The results of this process are alternative relationships and social organization, produced by developing and exercising moral imagination. Moral imagination is one way to switch a system out of a State 1 without violence. If the oppressors can be persuaded to see the world the way the oppressed do, perhaps then they will begin to introduce change instead of continuously attempting to combat it. Conversely, if those oppressed in a State 1 revolt and seize power without moral imagination, the result will simply be a new oppressoroppressed relationship ${ }^{7}$.

An example of a State 1 network in transition is the case of Eskom ${ }^{8}$. The example comes from case studies we have written to teach engineering ethics and engineering in relationship to economic development and the environment. Eskom is the fourth largest electrical utility company in the world and is based in South Africa. Engineers at the company have been faced with the issue of how to expand Eskom's service to include black South Africans who had previously been excluded under South Africa's apartheid regimes. Under apartheid, the utility maintained a State 1 relationship with respect to black South Africans. The utility denied service based on their exclusive representation that black South Africans should not be given electricity (In fact this was part of a larger State 1 network with respect to the white South African government who denied just about any right, technology, or service as a means to maintain

Proceedings of the 2001 American Society for Engineering Education Annual Conference \& Exposition Copyright (C) 2001, American Society for Engineering Education 
control over black South Africans). As the apartheid regime ended, Eskom set out on a program to electrify 1000 previously-excluded homes per day past the year 2000 and to continue the expansion program through 2025. The problem for engineers is how to accommodate this transition given the past very unequal social network relationships. In terms of network states, Eskom wants to get into a State 2 stable relationship with black South Africans in the wake of Apartheid. One problem is trying to change a culture of nonpayment for services. This is the flip side of being excluded from a service. How does Eskom get into a stable trading-zone where people will pay for a new service? How do engineers design a technological system to promote a more stable relationship between Eskom and black South Africans in the context of severe mistrust?

\section{State 2 Networks}

In a State 2 network, no one actor possesses a comprehensive understanding (or complete representation) with respect to a common issue. In this state relationships are maintained through a process of negotiating boundaries so that trades can take place that satisfy these multiple perspectives. The boundaries are most often maintained by the use of a boundary object that permits the linking of multiple perspectives. As long as the boundaries remain stable, so do the trading zones and relationships.

Within a State 2 network, the practitioners need to engage periodically a limited form of moral imagination. These periods occur when the trading zone boundaries become unstable and the trading relationship is threatened in a case where at least one practitioner wants to maintain the relationship. In such an instance, a practitioner must shift perspectives in an attempt to try to understand the bounds of the trading network and to try to offer a new boundary object to stabilize the boundaries. In order to make such an offer the practitioner must understand at least some aspect of the other network member's view, although the perspective does not have to be a complete or very deeply understood view.

For example, in the DesignTex case ${ }^{9}$, practitioners attempt to design and manufacture a commercial textile fabric for office interiors so that it will be safe for composting as a means of product disposal at the end of its useful life, thereby reducing environmental impacts through all stages of production and product disposal. As part of this process, Michael Braungart, a chemical engineer, needed to inspect and certify all chemical inputs according to strict environmental criteria, which can be summarized as "waste equals food," meaning all products and production emissions should be compatible with natural system metabolic processes. The problem became how could he build a State 2 relationship with chemical companies so that he could gain access to their chemical formulae so that he could do his evaluation and yet still honor the proprietary concerns of the chemical companies? In other words, he needed to develop a boundary object that could permit trading so that the chemical company could still function from the perspective of propriety and he and his network could still pursue their goal of waste equals food for the textile design. The boundary object in this case was an agreement to consult with the chemical company so that the company could learn how to improve its own processes in exchange for providing access to dye chemical formulae. Braungart created a consulting firm, the Environmental Protection Encouragement Agency, in Hamburg, Germany to act as a

Proceedings of the 2001 American Society for Engineering Education Annual Conference \& Exposition Copyright (C) 2001, American Society for Engineering Education 
boundary object to work with both chemical companies and environmental groups to promote environmental designs.

Like the Eskom case, previous to constructing this trading zone, chemical companies and environmental groups, such as Greenpeace, functioned in a State 1 relationship. The chemical companies maintained control over proprietary chemical information and used its influence to limit access and use of such information, even though such limitations have negative environmental consequences. On the flip side, environmental groups possessed knowledge on environmental processes but refused to share such perspectives by working openly with chemical companies out of mistrust. As a result, no trading took place, and no new designs were being implemented, and both sides exerted their efforts to maintain control, not innovate. Braungart's effort to construct a trading zone to change the relationship from a State 1 to a State 2 resulted in the sharing of information and successful new product development. A limited form of moral imagination by Braungart and managers at a chemical company permitted this shift to a State 2 .

In terms of the Eskom case, engineers designed a prepayment system that involved the use of tokens that had encoded on them electrical power credits that could be purchased by a local Eskom licensee or contractor. The tokens were inserted into readers that were installed in homes. In this way the engineers designed a trading zone that accommodated Eskom's perspective to receive payment for providing electricity and the South African citizens who wanted to be guaranteed they received electricity at a fair and equal price and that permitted the expansion of electrical connections to continue. The previous State 1 network was shifted to a State 2 because engineers were able to accommodate differing perspectives by constructing a boundary object (tokens) and trading zone (prepayment system) that functioned in terms of either perspective. Again, a limited from of moral imagination was involved because the different network groups never reached a complete understanding of the other group's perspective.

\section{State 3 Networks}

State 3 networks involve a complete and very deep sharing of perspectives, or mental models, among network members. In State 3, relationships are based on a sense of trust that goes beyond boundaries set by trading relationships, and each member of the State 3 network serves the interests of the other network members because of the shared understanding of perspectives. A State 3 always involves moral imagination among network members. The thorough understanding of other perspectives means that decisions in a State 3 network factor in the interests of other network members so that such interests receive a balanced consideration when decisions are made.

In the DesignTex case, the waste equals food perspective became commonly shared and permitted Susan Lyons of DesignTex, Albin Kaelin of Rohner Textil AG, Michael Braungart of the EPEA, and William McDonough to work together in a common network to design the fabric so that it was compostable. This perspective transformed Susan Lyon's vague design goal of producing an environmental product into a well-defined set of product requirements. It permitted Braungart's and McDonough's environmental expertise to coincide with profitability and functionality in design, and it permitted Albin Kaelin to solve his waste disposal problems.

Proceedings of the 2001 American Society for Engineering Education Annual Conference \& Exposition Copyright (C) 2001, American Society for Engineering Education 
The shared representation did more than just make it so that each of these practitioners could translate an outcome into their previous representations of their problems. The shared representation became the means to direct their actions to accommodate the new perspective, which they did to advance their own and common interests. The way these practitioners made this transition was to exercise moral imagination and consider their own problems and representations according to this new, waste equals food perspective, and then take action based on this shift in perspective.

\section{Final Comments}

We have observed that it is difficult for networks to remain in a State 3 network Over time, the centrifugal tendencies of actors' own networks of enterprise ${ }^{10}$ eventually push the shared representation beyond the limits of each actor's interests. The result we have observed is that the networks tend to settle in a stable State 2 network, with the common perspective reverting to a boundary object situation, permitting the network members to continue to work together through a trading zone. This observation highlights the difficulty in exercising moral imagination in practice given a complex and dynamic set of network interests and organizational relationships.

Such is the case with DesignTex, for which the actors have henceforth moved on to other projects, although the successful product, Climatex Lifecycle, continues to be manufactured and sold. This product and associated agreements serves as a boundary object for the network.

We are in the process of using this framework to discuss case studies that confront students with design decisions linking the social, ethical and technical aspects of engineering. DesignTex and Eskom are examples of such cases. Students navigate through a series of decisions that confront such questions as what constitutes an environmentally sustainable invention, how do you keep a global supply web aligned around a set of core principles and how can environmental design improve the traditional economic bottom-line? They also consider issues of global economic development and designing technologies that accommodate different cultural norms.

The framework helps illustrate that the network context that engineering students may find themselves one day will have an impact on their ability to engage in ethical decision making. Developing a skill at exercising moral imagination requires the ability to assess the conditions as to how others will react to the problem representations and solutions the engineering students will construct. Such an additional skill will have the practical benefit of making ethical and moral perspectives effective in practice.

\section{Bibliography}

1. Gorman, M. E., M. M. Mehalik, and Patricia Werhane. (2000). Ethical and environmental challenges to engineering. Englewood Cliffs, NJ, Prentice-Hall.

2. For a discussion of boundary objects, trading zones, and creoles in the sense we use these terms here, see Galison, P. (1997). Image \& Logic. Chicago, The Chicago University Press.

3. Hutchins, E. (1995). Cognition in the Wild. Cambridge, MA: MIT Press.

Proceedings of the 2001 American Society for Engineering Education Annual Conference \& Exposition Copyright (C) 2001, American Society for Engineering Education 
4. Latour, B. (1992). "Socio-technical graphs." Social Studies of Science 22 (1): 33-58.

5. Law, J., \& Callon, M. (1992). The life and death of an aircraft: A network analysis of technical change. In W. E. Bjiker \& J. Law (Eds.), Shaping technology, building society (pp. 21-52). Cambridge, MA: The MIT Press.

6. Diamond, J. (1997). Guns, germs and steel. New York: W. W. Norton \& Company.

7. Krishnamurti, J. (1970). The only revolution. New York, Harper \& Row. Krishnamurti, J. (1970). The urgency of change. New York, Harper \& Row.

8. Gorman et al.

9. Gorman et al.

10. Gruber, H. E. (1989). Networks of enterprise in creative scientific work. In B. Gholson, Shadish, W. R.,

Neimeyer, R. A., \& Houts, A. C. (Ed.), Psychology of Science: Contributions to Metascience (pp. 246-266).

Cambridge: Cambridge University Press.

\section{MICHAEL E. GORMAN}

Michael E. Gorman is Professor of Technology, Culture and Communications and Systems Engineering at the University of Virginia. He has published three books: Simulating Science (Indiana 1992), Transforming Nature (Kluwer 1998), and Ethical and Environmental Challenges to Engineering (Prentice Hall 2000) with Matthew Mehalik and Patricia Werhane.

\section{MATTHEW M. MEHALIK}

Matthew M. Mehalik is a Ph.D. student in Systems Engineering in an ethics and policy option. He has published cognitive analyses of the invention process and articles involving sustainable design, including "Sustainable Network Design: A Commercial Fabric Case Study” in Interfaces: Special Edition on Sustainable Business. 